\title{
O direito de propriedade em Fichte
}

\section{Jean-Christophe Merle}

Tradutor: Agemir Bavaresco, Danilo Vaz-Curado R. M. Costa, Paulo Roberto Konzen e Greice Ane Barbieri

\section{(2) OpenEdition \\ 1 Journals}

Edição electrónica

URL: http://journals.openedition.org/ref/246

DOI: $10.4000 /$ ref.246

ISSN: 2258-014X

Editora

EuroPhilosophie Editions

Refêrencia eletrónica

Jean-Christophe Merle, "O direito de propriedade em Fichte», Revista de Estud(i)os sobre Fichte [Online], 5 | 2012, posto online no dia 01 janeiro 2013, consultado o 08 setembro 2020. URL : http:// journals.openedition.org/ref/246; DOI : https://doi.org/10.4000/ref.246

Este documento foi criado de forma automática no dia 8 setembro 2020

(c) EuroPhilosophie 


\title{
O direito de propriedade em Fichte
}

\author{
Jean-Christophe Merle \\ Tradução : Agemir Bavaresco, Danilo Vaz-Curado R. M. Costa, Paulo Roberto Konzen e Greice Ane \\ Barbieri
}

\section{NOTA DO EDITOR}

Tradução: Agemir Bavaresco (PUCRS), Danilo Vaz-Curado R.M. Costa (UNICAP/UFRGS), Paulo Roberto Konzen (UFRGS) e Greice Ane Barbieri (UFRGS). NT.: O presente texto apareceu pela primeira vez, sob o título de Le droit de propriété chez Fichte, in: BIENENSTOCK \& CRAMPE-CASNABET, Dans quelle mesure la philosphie est pratique - Fichte, Hegel, ENS editions, 2000, p. 119-130.

1 A filosofia prática do idealismo alemão tem por característica submeter a prática a um princípio único, à liberdade entendida como autodeterminação. Um único idealista alemão concedeu à prática um primado absoluto: Fichte. Nisso que segue, um de meus dois objetivos será o de mostrar a radicalidade de seu pensamento a este respeito sobre o exemplo de sua teoria da propriedade, que constitui o coração de sua filosofia do direito, comparando notadamente sobre este ponto duas obras escritas quase ao mesmo tempo: o Fundamento do Direito Natural de Fichte e a Doutrina do Direito de Kant. Esta radicalidade constitui uma revolução copernicana que permite a passagem de teorias jusnaturalistas de aquisição às atuais teorias da justiça distributiva.

2 Mas, quando Kant ou Fichte aplicam o princípio do direito que lhes é comum, aparecem determinações que não decorrem somente do princípio jurídico, e que nos recordam que o idealismo alemão compreende a autodeterminação em um sentido forte, e não como simples livre-arbítrio (Willkür), ou liberdade de ação. Se o princípio do direito apenas concerne a co-existência das liberdades exteriores, certos argumentos e certas determinações da aplicação do princípio do direito, em Kant e Fichte, têm uma finalidade claramente diferente. É, a meu ver, a razão pela qual até vemos por toda a parte (na França, mas mesmo na Alemanha e nos Estados Unidos), nestes últimos anos, um renascimento do kantismo e mais modestamente do fichteanismo, em filosofia 
política e jurídica, este renascimento ignora ostensivamente o detalhe do direito kantiano e fichteano. De acordo com o direito kantiano e fichteano, em seu princípio, a ética jurídica universalista contemporânea apenas pode aplicá-los diferentemente a estes dois autores, fazendo intervir na aplicação do princípio do direito não a exigência da autodeterminação ou da autonomia em sentido forte, mas um princípio de justiça para livres-arbítrios individuais ${ }^{1}$.

3 O plano de fundo da filosofia da propriedade do idealismo alemão é a doutrina jusnaturalista clássica que eu caracterizarei em quatro pontos: (1) o dominium terrae do Gênese, a saber, o igual direito concedido a todos os homens de usar da natureza, (2) o pecado ou seus equivalentes secularizados que são o egoísmo, a ambição, a inimizade, as diferenças de talento e a assiduidade ao trabalho, etc., tornam impossível uma comunidade positiva de bens, e justificam a introdução da propriedade privada, (3) o direito do primeiro ocupante ${ }^{2}$, ou, de maneira mais ampla, o que Proudhon chamará mais tarde o direito de aubaine", no caso onde se fixa a aquisição de condições suplementares, por exemplo, em Locke, o trabalho ou a formação, (4) um elemento tornado necessário pela contradição existente entre o dominium terrae e o direito do primeiro ocupante, contradição que se manifesta pela existência de seres humanos não possuindo nenhuma propriedade e tributários para sua sobrevivência do emprego ou de esmolas oferecidas por outro. O quarto elemento é constituído por um conjunto de direitos, condições muito restritivas, tais que o direito de uso inocente, o direito de necessidade, a instituição de asilos públicos e de preços fixados pelo Estado para certos gêneros alimentícios de primeira necessidade, etc. Eles visam restabelecer parcialmente o dominium terrae, mantendo o quadro geral do direito do primeiro ocupante.

4 Enquanto que o dominium terrae se funda sobre uma comunidade de direitos entre os homens, comunidade relativa ao uso de uma coisa, o direito do primeiro ocupante estabelece a relação direta entre o indivíduo e uma coisa, e apenas define relações jurídicas entre os homens uma vez estabelecida a relação entre o indivíduo e a coisa. De modo mais geral, o direito natural define os direitos individuais sem os referir em primeiro lugar a uma comunidade jurídica.

5 Para o direito como para o uso teórico da razão pura, Kant efetua uma verdadeira revolução copernicana, definindo o direito como « o conceito do conjunto de condições às quais o arbítrio de um pode ser conforme com o arbítrio de outro segundo uma lei universal da liberdade $»^{3}$. Seis meses antes, Fichte formulava assim o conceito de direito: "Toda relação jurídica é determinada pela proposição: cada um limite a sua liberdade pela possibilidade da liberdade de outro $»^{4}$. Somente uma "vontade omnilateral $»^{5}$, a saber, a lei da comunidade jurídica, pode tornar a propriedade peremptória ou definitiva. Do conceito de direito, segundo Fichte, decorre que « cada cidadão tem [...] necessariamente uma propriedade $»^{6}$, proposição que o idealismo alemão reafirmará até Hegel, se bem que, como se sabe, Hegel critica alhures o igualitarismo fichteano em matéria de propriedade: «Todo homem deveria ter uma propriedade $»^{7}$. Como se sabe, Kant não tira esta conclusão, mas retoma, ao contrário, aplicando seu conceito de direito, três elementos incompatíveis do direito natural, a meu ver, com este conceito: (1) a propriedade peremptória somente faz, do ponto de vista quantitativo, sancionar o direito provisório do primeiro ocupante que Kant adota, substituindo assim para determinar o quantum da propriedade as condições da coexistência simultânea dos arbítrios por um critério de anterioridade temporal, (2) na continuidade da Doutrina do Direito, Kant efetua um rápido deslize nos termos 
utilizados para designar o objeto da propriedade definido como objeto do arbítrio, a saber, tanto para Kant como para Fichte um fim (Zweck). Kant passa assim do « uso de meu arbítrio relativamente a um objeto $»^{8}$ à $~ "$ coisa em si », em seguida a "um fundo de terra particular ${ }^{10} \mathrm{e}$, enfim, às « coisas corporais (substâncias) $»^{11}$. Enquanto objeto do arbítrio, o fim depende da razão prática, a substância das coisas corporais remete à razão teórica, do mesmo modo que a prioridade temporal inclui-se na noção de primeira ocupação. Kant omite-se assim em distinguir a substância da terra dos usos da terra. Este ponto é ligado ao precedente, pois se a propriedade como objeto de arbitrio era definida por Kant como ela deveria ser, isto é, como um direito de uso e não como um direito sobre uma substância, a primeira ocupação de uma substância não seria constituir um modo de aquisição de uma propriedade. (3) Estes dois elementos incompatíveis com o conceito kantiano do direito introduzido, não seria de se surpreender, que Kant, como os jusnaturalistas, recorra à solução dos asilos públicos para os pobres desprovidos de propriedade, o que não lhes dá de forma alguma uma propriedade, mas somente a estrita subsistência.

6 O Fundamento do Direito Natural indica a solução alternativa aos dois primeiros pontos, em sua Dedução do direito originário, e ao terceiro ponto, em seu Contrato civil e na sua Legislação civil. Começarei por abordar a alternativa ao ponto (2), antes de abordar àquela do ponto (1). Com efeito, no meu entender, é a adoção do direito do primeiro ocupante como modo de aquisição da propriedade (1) que conduz Kant a mudar radicalmente sua definição da propriedade (2). Ao inverso, é com a permanência fiel à definição da propriedade ditada pelo conceito kantiano e fichteano do direito (2) que Fichte resolve a questão da atribuição das propriedades de uma maneira mais fiel do que a do conceito kantiano (1).

7 Num primeiro olhar, poderia parecer que Fichte procede de maneira semelhante àquela de Kant. Kant trata do meu e do teu no estado de natureza (direito privado) antes de passar ao meu e ao teu no estado jurídico em geral (direito público). Após ter lembrado o resultado de sua dedução do conceito de direito e de sua aplicabilidade, a saber, "apenas pode-se falar de direitos sob a condição de que uma pessoa seja representada como pessoa, ou seja, como indivíduo, por consequência seja relacionada a outros indivíduos ", isto é, "as limitações tornadas necessárias pelos direitos dos outros $»^{12}$, Fichte decompõe esta definição. Esta operação de abstração parte de direitos originários fictícios, ou condições da personalidade, para reconstruir os direitos como solução ao possível conflito entre os direitos originários das diferentes pessoas. 0 método construtivista e individualista implementado por Fichte difere, portanto, profundamente daquele de Kant, nisso que Kant sublinha acerca do estado de natureza e do estado civil, isto é, do direito privado e do direito público, que «a matéria é a mesma nos dois casos: aquela do direito privado. As leis [do direito público] apenas concernem, portanto, à forma jurídica [...] $\aleph^{13}$. Em Fichte, o contrato público de propriedade determinará não somente a forma, mas também a matéria da propriedade. $\mathrm{O}$ individualismo tem um caráter puramente metodológico.

8 (2) No quadro desta ficção metodológica, Fichte define a propriedade como « a parte do mundo sensível que me é conhecida e que é submetida aos meus fins, mesmo se fosse apenas em pensamento [...] $»^{14}$. A expressão « mesmo se fosse apenas em pensamento » lembra que o direito de propriedade não é submetido a uma possessão anterior, nem à nenhuma condição física anterior. Fichte rejeita notadamente um a um o « velho debate para saber se o direito de propriedade sobre uma coisa [Ding] é fundado exclusivamente 
pela formação daquela ou se ele é já fundado pela vontade do possuidor ». A segunda tese visada é apenas a do direito do direito do primeiro ocupante. Se Fichte não o designa por seu nome, é para sublinhar o que esta tese tem de comum com a outra tese mencionada, a saber, uma tese lockeana amputada da cláusula restritiva que exige que ela permaneça suficiente para o outro. As duas teses fixam uma condição física à aquisição e adicionam somente uma condição não física: a vontade ou a atividade. Fichte suprime a condição física, o que Kant não tinha realizado. A expressão " submetida aos meus fins, mesmo se fosse apenas em pensamento » sublinha isso. Por outro lado, não é preciso compreender a "parte do mundo sensível » submetida a estes fins em um sentido puramente espacial, como uma coisa. Além disso, o «direito à persistência da liberdade absoluta e à inviolabilidade absoluta do corpo ", o direito originário consiste no « direito à persistência de nossa livre influência sobre o mundo sensível em seu conjunto $»^{15}$. No contrato público de propriedade, Fichte tira a consequência de que a propriedade designa uma esfera da liberdade que "contém certos objetos que são determinados pela liberdade que lhe é reconhecida». E ele prossegue: «Ainda que distante, por consequência, que se entenda a liberdade que lhe é reconhecida, ainda que distante, mas não mais se entende seu direito de propriedade sobre os objetos. Ele os recebe exclusivamente em vista de um certo uso. É uma atividade determinada que constitui o objeto do contrato de propriedade $»^{16}$. Segue-se que uma mesma coisa pode ser atribuída a vários usos e, portanto, a vários proprietários, se estes usos não se contradizem, é que esta mesma coisa pode ser utilizada, além disso, por todos ainda para outros usos, se estes últimos não prejudicarem os primeiros ${ }^{17}$. A " parte do mundo sensível » não é, pois, entendida como uma parte das coisas materiais, mas como uma parte dos usos possíveis das coisas materiais.

9 (1) A esta revolução copernicana na definição do direito de propriedade está ligada uma segunda revolução copernicana, na atribuição do direito de propriedade. Em oposição ao direito natural, Fichte não põe nem resolve a questão em termos de aquisição por um indivíduo de uma coisa que não pertence ainda a ninguém (res nullius), o princípio dos indiscerníveis torna impossível a existência simultânea de vários primeiros possuidores de uma mesma coisa. Fichte construiu o direito de propriedade a partir do direito originário fictício de propriedade, da possibilidade de colisão entre os direitos originários ou os fins dos diferentes indivíduos, e da solução que é a limitação mútua destes direitos. Ora, a limitação mútua constitui já o princípio do direito. É necessário, pois, substituir na definição do direito o termo liberdade exterior por sua definição que comporta, além da persistência e da intangibilidade do corpo, a persistência da ação livre na totalidade do mundo. Fichte escreve: "toda relação jurídica é determinada pela proposição: cada um limita sua liberdade pela possibilidade da liberdade do outro. - $O$ que pertence ao ser livre em geral e em si é agora elucidado. Para um ser livre infinito tal que aquele que se descreveu, a liberdade de todos, à exceção de um apenas, seria suprimida, e ela seria aniquilada igualmente em sua existência física [...] esta contradição se resolve desde que [...] cada uma das partes em colisão limite sua liberdade. Como nas teorias atuais da justiça, a propriedade nem preexiste ao direito das relações entre os indivíduos, mas depende da justiça distributiva ». Fichte aplica mais adiante sua construção indicando que a colisão se manifesta pela « declaração » pelos indivíduos de seus fins, depois, pela limitação pelo « reconhecimento mútuo » que une a vontade de muitos em uma só vontade. A Fichte resta apenas universalizar este conflito e esta solução, no espaço, projetando-a e 
aplicando-a em escala mundial, e no tempo, regulando o avanço do modo de aquisição válido para o futuro. Isto constitui somente a esquematização do conceito de direito no tempo e no espaço ${ }^{18}$.

10 Após ter operado esta esquematização do princípio do direito em um acordo sobre a limitação mútua de direitos originários de propriedade, ou ainda o "equilíbrio do direito » e, portanto, após ter mostrado o processo de aplicação, ele retorna, um ano mais tarde, à segunda parte do Fundamento do Direito Natural «de explicitar completamente » em um « contrato de propriedade » este equilíbrio apenas « descrito » em uma "dedução do direito originário ». Por trás do termo vago "de explicitação completa " é preciso ler a adoção de um princípio de determinação material do quantum da propriedade, por oposição ao princípio de determinação puramente formal do quantum que é o reconhecimento mútuo ou o acordo dos indivíduos em uma só vontade.

11 (3) É este princípio material de determinação que fornece uma alternativa à solução proposta por Kant, e antes de Kant pelo direito natural, ao problema dos pobres que não são proprietários e não podem assegurar sua subsistência. É também a adoção deste princípio de determinação material que constitui a bifurcação entre a via emprestada pelo idealismo fichteano da autonomia absoluta e àquela da filosofia do direito contemporâneo que reclama princípios kantianos e fichteanos.

12 Com efeito, a filosofia do direito contemporâneo adotaria como princípio da repartição um princípio de justiça, princípio que se reclamaria de uma certa igualdade entre os cidadãos, igualmente que restaria precisar, e que poderia ser por exemplo a igualdade de recursos de Dworkin, o princípio da diferença de Rawls, ou, de maneira mais clássica, uma igualdade de renda, de bem-estar, ou ainda de levar em conta na maximização do bem-estar, etc. Estes princípios teriam por efeito determinar completamente a partilha por efetuar.

13 Encontram-se no Fundamento do Direito Natural e mais geralmente no conceito kantianofichteano do direito vários elementos que tendem nesta direção. Fichte fala de um « equilíbrio do direito », o qual lembra a maneira em que Kant esquematiza o direito na Doutrina do Direito, a saber, como « uma linha reta » oposta à oblíqua, como « a posição de duas linhas se cortando ou tocando, de tal modo que pode haver apenas uma só linha (a perpendicular), que não inclina mais de um lado do que do outro e que divide o espaço em duas partes iguais; seguindo aquela analogia, igualmente a doutrina do direito quer conhecer precisamente (com uma exatidão matemática) o que para cada um é o seu [...]».

14 Para saber qual equilíbrio adotar entre os direitos de propriedade originários dos indivíduos, a saber, entre os fins dos indivíduos, é necessário saber quais são estes fins. Ora, Fichte reformula assim esta questão: «[...] estes fins podem ser bem diferentes e compreendidos no uso de um mesmo objeto, eles podem pois ser para objetos de espécies diferentes. A questão que se põe é saber se todos os fins possíveis do cidadão não podem, no entanto, se subordinar a um único fim $»^{19}$. Ao fim de sua resposta, Fichte conclui: «O fim supremo e universal de toda a atividade livre é, pois, o de poder viver. Este fim, cada homem o possui, e por consequência, desde que a liberdade em geral é garantida, ela é garantida. Sem o atingir deste fim, a liberdade e a permanência da pessoa não seriam jamais possíveis $»^{20}$. Reportamo-nos agora aos dois pontos que constituem para Fichte o "direito originário » de cada homem: «1) o direito à persistência da liberdade absoluta e à inviolabilidade absoluta do corpo [...], 2) o direito 
à persistência de nossa livre influência sobre o mundo sensível em seu conjunto $»^{21}$. Nas linhas precedentes, o raciocínio de Fichte é que (a) a raridade de recursos não é tal que a subsistência de todos não possa ser assegurada, (b) que a subsistência (o poder viver) é a condição sine qua non do direito originário (1), a saber, a liberdade e a persistência do corpo, de sorte que este fim pode ser atribuído a todo homem; (c) que, além disso, a subsistência é o «fim supremo e [o mais ${ }^{22}$ ] universal de toda atividade livre ». Que a subsistência seja o fim mais universal está claro, posto que ela é a condição sine qua non da persistência do corpo, portanto, de toda a ação. No entanto, fazer o fim supremo voltar a atribuir como o mais alto fim a nossa liberdade de agir sobre o mundo sensível, um fim que o mundo sensível ele mesmo torna necessário. Este ponto coloca três questões: $\alpha$ ) por qual razão invocar implicitamente uma hierarquia de fins que pode se propor o livre arbítrio ${ }^{23}$ ? $\beta$ ) Mesmo caso se aceite a existência de uma tal hierarquia, por que o fim supremo da liberdade seria submetido ao determinismo da natureza sensível?; $\gamma$ ) na ausência de menção a todo outro fim, segundo qual critério dar um direito ou limitar os outros fins que o homem pode se propor, e se Fichte não indica o critério, por que este desinteresse e este tratamento somente parcial do direito aplicado?

15 Para responder estas questões é preciso começar por retificar a segunda questão. Adotar por fim supremo do livre arbítrio a subsistência não faz voltar a submissão ao determinismo da natureza sensível o fim supremo do livre arbítrio. Com efeito, a subsistência não é introduzida por Fichte como um simples dado antropológico, mas num argumento teleológico. Fichte afirma que «a natureza destinou os homens [...] à liberdade, a saber, à atividade ». Com efeito, os homens têm tanto um fim, cuja busca é condicionada por sua subsistência presente, quanto eles não o têm, e a « fome e a sede [...] a necessidade de alimento lhes é o único móvel originário [...]». Tais são as " disposições " que a natureza toma " para impelir os homens à atividade $»^{24}$. É por isso que Fichte escreve: «Poder viver é a propriedade absoluta e inalienável de todos os homens. Foi lhe reconhecido uma certa esfera de objetos exclusivamente para um certo uso, isso temos visto. Mas, o fim último deste uso é poder viver. [...] É o princípio de toda constituição racional: todo homem deve poder viver de seu trabalho $»^{25}$. De fato, Fichte propõe, por exemplo, proceder uma redistribuição de terras se certos camponeses não podem viver de seu trabalho. Como se vê, o argumento de Fichte consiste em promover o direito ao trabalho para assegurar a subsistência, mas, ao apresentar a subsistência como resposta teleológica ao problema de saber como impelir os homens à atividade, incluídos aí os homens preguiçosos. Pois desenvolver a atividade é o que exige a busca da autonomia, do eu, enquanto que a preguiça, a passividade, é heteronomia. Promover o direito ao trabalho é, portanto, um requisito ético.

Se a satisfação da fome e da sede é para Fichte o « fim último do Estado e de toda a vida humana ", Fichte toma cuidado de precisar que ela apenas « dura tanto tempo quanto o homem permanece simplesmente sob a direção da natureza e não se eleva para a liberdade de uma existência superior ${ }^{26}$. A Doutrina da Vida Ética explicita, em sua " divisão das ocupações humanas possíveis ${ }^{27}$, o que Fichte entende por uma existência superior. Ele aí distingue, com efeito, duas categorias de ocupações, todas destinadas a promover o fim da razão, que é a constituição de uma comunidade de seres racionais que seja também uma comunidade moral e espiritual. A primeira, a classe superior, composta de sábios, funcionários, instrutores morais e artistas, age diretamente sobre a comunidade de seres racionais, enquanto que a segunda classe, dita inferior, apenas 
atua indiretamente sobre esta comunidade lhe assegurando a subsistência sem a qual aquela não poderia progredir, uma vez que o Estado e o direito não existiriam. No Sistema da Vida Ética, Fichte não despreza de maneira alguma esta classe inferior que ele qualifica de sublime, pois ela domina a natureza e, assim nos libera do determinismo natural. No Fundamento do Direito Natural, a exposição das diferentes profissões apenas compreende as profissões inferiores, e encontra-se precedida por uma página sobre os degraus de organização na natureza, o homem se encontrando no mais alto degrau, pois ele não se alimenta da matéria bruta, mas de corpos orgânicos que se alimentam de outros corpos orgânicos, e mesmo articulados, pois ele deve ir procurar, ele mesmo, sua subsistência que a natureza não lhe proporciona. Tal é « a disposição que a natureza nos impõe para nos forçar à livre atividade $\aleph^{28}$. Fichte sublinha em seguida que o camponês aprende não certamente a "transformar ", mas a " conhecer e a dirigir » as leis da natureza, adquirindo, assim, "a capacidade de fazer progredir e aumentar a organização ». Assim, antes mesmo do nível mais elevado do artesão, que Fichte nomeia de " artista ", por oposição aos simples produtores que apenas fazem ajudar a natureza a produzir seus recursos, o que Fichte põe em relevo é a emancipação do homem em relação à natureza.

Observa-se que o artesanato não é necessário à estrita subsistência. De fato, após seu primeiro argumento teleológico, Fichte não fala mais da satisfação da fome e da sede, mas do "poder viver ». Mais adiante, ele prescreve a adaptação das efetividades das profissões à evolução das necessidades e de repartir as terras não cultivadas com aqueles que as demandam para a satisfação de suas necessidades. 0 "poder viver " parece, portanto, ir além da simples subsistência. De todo modo, Fichte exclui o luxo e recomenda a não introdução de produtos que pudessem engendrar novas necessidades duráveis. Satisfazer as necessidades sem as multiplicar, tal é precisamente a via de emancipação da natureza, em oposição à fome que nos torna absolutamente dependentes da natureza, e da multiplicação das necessidades, que nos torna de novo dependentes. Quando, na Doutrina do Direito de 1812, Fichte trata da questão da economia, do investimento, do aumento da produtividade, etc., ele escolherá dedicar ao lazer uma importante parte do crescimento, a fim de nos dedicar à nossa destinação moral e espiritual.

18 Naturalmente, como eu já ensaiei mostrar alhures, Fichte não entende colocar em questão a livre disposição de cada um dos frutos de seu trabalho, incluído aí sua dissipação ou sua fruição mais imediata. Não resta dúvida de que o idealismo fichteano da autonomia difere claramente das atuais teorias universalistas da justiça (e não da autonomia em sentido forte), as quais defendem também a emancipação, e isso ao menos em dois pontos essenciais: 1) o critério da justiça distributiva: se Fichte reconhece um direito igual à subsistência pelo trabalho, ele não fixa nenhum quantum, nem estabelece qualquer igualdade de qualquer sorte pela distribuição do restante da propriedade. Mas, Fichte aplicará em 0 Estado comercial fechado, em 1800, um princípio de igualdade para o quantum da propriedade, de sorte que a verdadeira diferença entre Fichte e as teorias da justiça atuais consiste sobre 2) a exigência de progresso para o conjunto da comunidade: Fichte entende promover a disponibilidade dos cidadãos à sua destinação espiritual, enquanto que as teorias da justiça atuais entendem oferecer aos indivíduos o mais largo campo de opções ao seu livre arbítrio, observando a neutralidade entre estas opções. A divergência não consiste, portanto, sobre o princípio distributivo do direito, mas sobre a orientação que a comunidade jurídica entende dar ao progresso: seja orientar seus cidadãos em face de uma concepção forte de autonomia 
da vontade, o que passa pela via de um forte paternalismo, seja deixar à liberdade de ação dos indivíduos a escolha completa de seus fins. Sem concluir, eu ousarei apenas sugerir que se acorde sobre a segunda opção, por rejeitar a via paternalista, não sem experimentar alguma nostalgia para com a primeira opção face às errâncias de certos livres arbítrios.

\section{NOTAS}

1. No que concerne a Kant, cf., por exemplo, J.-C. MERLE, „Funktionen, Befugnisse und Zwecke der Staatsverwaltung. Zur allgemeinem Anmerkung zu § 49, B-D“, in: O. HöFFE (ed.) Kants Rechtslehre, Berlim: Akademie-Verlag, 1999.

2. Deixo aqui de lado os casos particulares, tais como a aquisição pela conquista.

\#. Nota do tradutor: jus albinatus - direito que tinha o soberano de ficar com os bens do forasteiro falecido em suas terras.

3. E. KANT, Doutrina do Direito, Trad. J. e O. Masson, in: Oeuvres Completes, ed. F. Alquiè, Paris, Gallimard, coleção Pléiade, 1986, t. III, p. 479 (edição da Academia de Berlim: I. Kant, Gesammelte Werke Schriften, Berlim: Reimer, 1907, RL AA 06, 230).

4. J. G. FICHTE, Fondement du droit naturel selon les principes de la Doctrine de la science (FDNfr). Trad.

A. Renaut, Paris: PUF, 1984, p. 136 (GA I/3, 411 GNR).

5. Doutrina do Direito, Pléiade III, 518; RL AA 06, 263.

6. FDNfr 207, GA I/4, 8 GNR.

7. G. W. F. HEGEL. Princípios da Filosofia do Direito ou Direito Natural e Ciência do Estado em compêndio. Trad. R. Derathé e J. P. Frick, J. Vrin, 1975, § 49, adendo, p. 106.

8. Doutrina do Direito, § 2, Pléiade III, 495; RL AA 06, 246.

9. Doutrina do Direito, § 5, Pléiade III, 499; RL AA 06, 249.

10. Doutrina do Direito, § 6, Pléiade III, 500-501; RL AA 06, 250.

11. Doutrina do Direito, § 10, Pléiade III, 512; RL AA 06, 259.

12. FDNfr, 126, GA I/3, 403 GNR.

13. Doutrina do Direito, § 41, Pléiade III, 573; RL AA 06, 306.

14. FDNfr, 131, GA I,/3, 407 GNR.

15. FDNfr, 134, GA I/3, 409 GNR.

16. FDNfr, 222, GA I/4, 20 GNR.

17. Encontra-se aí uma justificação e uma extensão sistemática disto que o direito natural reconhecia como um direito não exigível sob o nome de jus innoxia, ou direito de uso inocente: cf. J.C. MERLE, Justice et progrés, Paris: PUF, 1997, p. 54 e s.

18. Não abordarei aqui a questão de saber se Fichte realiza esta universalização no tempo e no espaço de uma maneira adequada nas páginas de precisões da dedução dos direitos originários. Fichte escolhe confiar a resolução das colisões da propriedade entre cidadãos ao Estado, isto é, a uma terceira instância e comum a todos os cidadãos. Ao contrário, no caso dos conflitos entre Estados, Fichte opta por uma solução mediante convenções bilaterais, sem uma terceira instância. A razão invocada por Fichte para justificar uma tal assimetria entre a solução proposta para os conflitos entre cidadãos e aquela proposta para os conflitos entre os Estados é que apenas os Estados limítrofes entram em relação entre si, ao menos quando eles não são separados por obstáculos naturais. Este argumento é tão fraco que Fichte reconhece em seguida que, apesar da 
descontinuidade geográfica, todos os Estados entram em relação entre si, notadamente pelas relações que mantêm entre si os seus cidadãos. No que concerne à universalização temporal, a adoção do direito do primeiro ocupante para regulamentar a questão da aquisição futura é apoiada pelo argumento segundo o qual no que se refere às coisas que ninguém quer fazer uso atualmente, não se pode temer colisão entre os fins simultâneos de diferentes indivíduos, pois sempre haverá alguém capaz de determinar a prioridade temporal. Este argumento parece pouco provável, mesmo para Fichte, que escreve na Legislação civil que os «terrenos não cultivados devem ser repartidos, desde que a necessidade dos indivíduos os demande (FDNfr 231, GA I/4, 28 GNR). De fato, no direito aplicado, Fichte concebe a atribuição futura da propriedade da mesma maneira do que a atribuição original, a saber, por repartição.

19. FDNfr 222, GA I/ 4, 21 GNR.

20. FDNfr 223, GA I/4, 22 GNR.

21. FDNfr 134, GA I/3, 409 GNR.

22. Eu completo a tradução de A. Renaut.

23. Uma passagem da Dedução do direito originário confirma que, para Fichte, uma tal hierarquia existe, enquanto se mencionam outros fins, que não são levados em consideração na determinação do quantum da propriedade no contrato de propriedade: « Não há direito particular à conservação de si [...] mesmo se nós tivermos um fim menos importante, não se teria o direito de perturbar nossa liberdade, pois, de uma maneira geral, não se tem o direito de a perturbar » (FDNfr 134, GA I/3, 409 GNR).

24. FDNfr $222, \mathrm{GA} \mathrm{I} / 4,21 \mathrm{GNR}$.

25. FDNfr $223, \mathrm{GA} \mathrm{I} / 4,22 \mathrm{GNR}$.

26. FDNfr 222, GA I/4, 21-22 GNR.

27. J. G. FICHTE, Le système de l 'éthique selon les principes de la doctrine de la science. Trad. P. Naulin, Paris: PUF, 1986, § 28.

28. FDNfr 226, GA I/4, 24 GNR.

\section{RESUMOS}

This article aims at giving an explanation of Fichte's theory of property in his Foundations of Natural Right by comparing it with Kant's theory of property in his Metaphysics of morals. The main thesis is that Fichte's conception of property represents the transit from a jus naturalist comprehension of property, which can be found in theories of natural law as well as in Kant's philosophy of right, to an understanding of property in terms of distributive justice in the acquisition of goods. The central point in the distinction between Fichte's and Kant's conceptions of property consists in that Fichte radicalizes the Kantian project of self-determination of property in the state of nature as well as in the legal state. In doing so, Fichte's theory of property overcomes the duality, present in the acquisition of property, between the right of first purchase and the exercise of the will on the thing possessed. It will be shown that individualism in Fichte is purely methodological and property only emerges as a means of achieving community. Hence, Fichte overcomes the idea of the owner acting out of free will in favour of an emancipatory conception of property. 
ÍNDICE

Keywords: autonomy, philosophy of right, property, Fichte, Kant

\section{AUTORES}

JEAN-CHRISTOPHE MERLE

Universität des Saarlandes 